\title{
Clinical and Nutritional Determinants of Extrauterine Growth Restriction Among Very Low Birth Weight Infants
}

This article was published in the following Dove Press journal: International Journal of General Medicine

\section{Wasim Khasawneh Mohammad Khassawneh Mai Mazin Muath Al-Theiabat Tuka Alquraan \\ Department of Pediatrics and Neonatology, Faculty of Medicine, Jordan University of Science and Technology, Irbid, Jordan}

Correspondence: Wasim Khasawneh Department of Pediatrics and Neonatology, Jordan University of Science and Technology, PO Box 3030, Irbid 22110, Jordan

Tel +962796041117

Fax +96227095777

Email wakhasawneh@just.edu.jo
Purpose: To identify the clinical and nutritional factors associated with extrauterine growth restriction (EUGR) among very low birth weight infants (VLBW) in a tertiary hospital in Jordan. Patients and Methods: We conducted a retrospective analysis of all VLBW infants admitted at King Abdullah University Hospital between July 2015 and June 2020. Clinical factors, nutritional intake, and growth parameters were collected and analyzed. A multilogistic regression model was applied to identify factors associated with EUGR.

Results: Of the 247 VLBW infants included in analysis, 112 (45\%) were males, $30(12 \%)$ were below $1000 \mathrm{~g}$, and $72(29 \%)$ were small for gestational age (SGA). EUGR was diagnosed in $198(80 \%)$ at discharge. The rates of EUGR among SGA and non-SGA infants were $97 \%$ and $73 \%$, respectively. The EUGR infants had a higher gestational age (30.7 vs 29.8 weeks, $p=0.04$ ), a lower birth weight (1209 vs $1300 \mathrm{~g}, p=0.005)$, a longer ventilatory support (5.7 vs 2.2 days, $p=0.03)$, a higher incidence of sepsis $(23 \%$ vs $10 \%, p=0.05)$, and a longer hospitalization (46 vs 38 days, $p=0.03$ ). With multilogistic regression model, the factors associated with EUGR include small-for-gestational age (AOR 9, 95\% C.I. 2, 50), $>3$-day delay in feeding initiation (AOR 3.8, 95\% C.I. 1.2,10), >14-day delay in achieving full feeds (AOR 3.3, 95\% C.I. 1.2, 8), <3 $\mathrm{g} / \mathrm{kg}$ of protein intake on the 8 th day (AOR 2.1, $95 \%$ C.I. $1.1,4.1$ ),$<100 \mathrm{kcal} / \mathrm{kg}$ of total caloric intake on the 15 th day (AOR 3.8, $95 \%$ C.I. 1.6, 8.9), and occurrence of sepsis (AOR 3, 95\% C.I. 1.1, 9).

Conclusion: The rate of EUGR in our unit is high. In addition to being SGA at birth, sepsis and suboptimal protein and caloric intake in the first two weeks of life were significantly associated with this complication. A more aggressive enteral and parenteral nutritional approach is needed to minimize postnatal growth delay.

Keywords: neonatal nutrition, EUGR, Jordan, VLBW infants

\section{Introduction}

Nutritional support of premature infants, particularly those with very low birth weight (VLBW; less than $1500 \mathrm{~g}$ ), is one of the major challenges that face neonatologists. In the presence of normal intrauterine environment, the fetal weight increases 3- to 4-fold between 26 and 40 weeks of gestation. ${ }^{1}$ The first week of life is considered the most critical period that determines growth and neurodevelopment at later age. Premature delivery interrupts this normal physiologic process, and premature babies are consequently born with inadequate nutritional stores. Infants with intrauterine growth restriction (IUGR) and those born small for gestational age (SGA) are expected to have a higher risk. ${ }^{2}$ 
After delivery, the goal is to provide nutritional support to the premature infant at a rate and contents that simulate the intrauterine environment. ${ }^{3}$ However, prematurityrelated morbidities that limit the nutritional intake or increase the energy expenditure act as major barriers. ${ }^{4}$ Factors that limit the nutritional and caloric intake include the necessity of fluid restriction, the lack of routinely used central venous access (such as umbilical catheters) beyond the first week of life, the lack or shortage of proper total parenteral nutrition (TPN) service, the limit in the allowed glucose infusion rate and parenteral protein administration based on glycemic control and renal function, and the commonly encountered feeding intolerance resulting in frequent interruptions of enteral feeding. ${ }^{5}$ On the other hand, the increased work of breathing and issues related to thermal regulation and processing of enteral feeds increase energy expenditure and contribute to the negative energy balance. Furthermore, prolonged assisted ventilation and the use of methylxanthines and diuretics, among other iatrogenic interventions, contribute to the nutritional deficits. $^{6}$

Extrauterine growth restriction (EUGR) refers to postnatal nutritional insufficiency causing a lag of growth pattern manifested by growth parameters below certain reference levels. EUGR has been reported to affect $40-95 \%$ of premature infants. EUGR is defined by a weight, length, or head circumference value that falls below the 10th percentile of the expected intrauterine growth at 36- to 40-week postconceptional age (PCA) or at discharge. ${ }^{7}$ More recently, a longitudinal definition, based on $>1$ standard deviation reduction in weight $z$ score between birth and discharge, has been more frequently used..$^{5}$ The wide variation in the rate of EUGR is related to the heterogeneity of the inclusion criteria and the used definition in different reports. In the USA, the California Perinatal Health Cooperation Organization reported a EUGR rate of 50\% in the period 2005-2012. ${ }^{8}$ In China, $70 \%$ of VLBW infants were reported to have EUGR. ${ }^{9}$ Several other studies reported an association between postnatal growth pattern and growth and neurodevelopment during infancy and childhood. ${ }^{7,10,11}$

Several studies evaluated the factors that contribute to EUGR. These factors include antenatal growth status, postnatal nutritional support, co-morbidities, and genetic and epigenetic factors. ${ }^{12,13}$ Studies have shown that the risk of EUGR increases with decreasing birth weight and gestational age and is more obviously seen in the more mature SGA infants. ${ }^{13}$ Another factor that affects the risk of EUGR is the duration of initial weight loss in the neonatal period. Infants who require longer time to regain birth weight are more likely to develop EUGR and impaired growth as they grow older. ${ }^{14}$ Enteral nutrition is superior to parenteral nutrition in achieving adequate growth in the neonatal period. ${ }^{13}$ Simultaneously, special attention should be paid to optimizing nutrition during the transitioning phase from TPN to enteral nutrition as inadequate protein and energy supply during this critical period is not uncommon and could significantly contribute to postnatal growth failure. ${ }^{15}$ Postnatal morbidities like prolonged ventilatory support, chronic lung disease, sepsis, and necrotizing enterocolitis (NEC) correlate with higher rates of EUGR among premature infants, particularly ELBW infants. ${ }^{16}$ In addition, genomic imprinting is one of the major reported genetic mechanisms that has been studied and strongly linked to impaired growth and development. ${ }^{12}$

In Jordan and nearby countries in the region, research is limited about the nutritional support in neonatal ICUs, and there have been no studies to evaluate the rate or causes of EUGR. A single-center limited prospective report from Jordan University Hospital reviewed the local nutritional practice among 43 VLBW infants and concluded that utilization of breastmilk and early fortification after reaching full feeds are essential factors in optimizing neonatal nutrition. ${ }^{17}$

Our study was conducted to assess the rate of EUGR and identify its determinants among VLBW infants admitted during the last five years at King Abdullah University Hospital (KAUH), the major academic referral institution in the north of Jordan.

\section{Patients and Methods}

This is a retrospective analysis of all VLBW infants admitted at KAUH in the period July 2015 to June 2020. The study was approved by the institutional review board (IRB) at Jordan University of Science and Technology and given an IRB number (518-2020).

A list of all infants born during the study period was extracted from the hospital electronic database. All infants with a birth weight of less than $1500 \mathrm{~g}$ were eligible to be included. Excluded from the analysis were all infants with congenital anomalies or major chromosomal abnormalities, infants who were transferred to other institutions, and infants who died before reaching 36-week PCA. Parental consent was waived since this study involves chart review. 
Data were collected about demographic characteristics including gestational age (GA), gender, maternal age, mode of delivery, number of gestations, assisted pregnancy, and antenatal steroid administration.

Collected variables about nutritional status included age at feeding initiation, age at reaching full enteral feeds, age at regaining birth weight, and protein and caloric intake on days $1,8,15$, and at discharge. Growth parameter values and corresponding percentiles were documented at birth and at discharge using Fenton growth charts for premature infants. ${ }^{18}$

Data were also collected about respiratory support, morbidities such as intraventricular hemorrhage (IVH), patent ductus arteriosus (PDA), NEC, sepsis, and blood transfusion.

The term small for gestational age (SGA) was applied for newborns with birth weight below the 10th percentile based on the estimated GA. For analysis, EUGR was defined by weight at discharge that is below the 10th percentile of the expected intrauterine weight based on the estimated GA. ${ }^{18}$

In our unit, the following hospital-based protocols are applied while caring for VLBW infants:

\section{Enteral Nutrition (EN)}

Enteral gavage feeding is initiated between day 1 and 5 based on the baby's respiratory and hemodynamic status. Mothers are encouraged to pump and provide expressed breastmilk (EBM) for their infants. Premature formula (caloric density of 24 calories per ounce) is used where EBM is not available. Trophic feeding is usually given for one to three days then advanced by 15 to $20 \mathrm{~mL} / \mathrm{kg} /$ day as tolerated till reaching $140-160 \mathrm{~mL} / \mathrm{kg} /$ day. Feeding is fortified using formula powder, and caloric density is gradually increased till reaching 30 calories per ounce for a goal of $120-140$ calories $/ \mathrm{kg} /$ day. Gavage feeding is initially given at 2-hour intervals and switched to 3-hour intervals after the infant's weight reaches $1500 \mathrm{~g}$. Oral trials are gradually allowed after a PCA of 33-34 weeks if the overall clinical status is stable.

\section{Parenteral Nutrition (PN)}

After birth, intravenous fluid infusion is commenced at $80 \mathrm{~mL} / \mathrm{kg}$ /day for VLBW infants and $100 \mathrm{~mL} / \mathrm{kg} /$ day for ELBW infants. The infusion rate is advanced by $20 \mathrm{~mL} / \mathrm{kg} /$ day on a daily basis till reaching a maximum fluid intake of $140-160 \mathrm{~mL} / \mathrm{kg} /$ day including enteral feeds. The starting fluid consists of $10 \%$ dextrose solution mixed with $5 \%$ amino-acid solution at $1 \mathrm{~g} / \mathrm{kg} / \mathrm{day}$. Dextrose concentration is titrated to maintain blood glucose level between 80 and $180 \mathrm{mg} / \mathrm{dL}$, while protein administration is advanced by $1 \mathrm{~g} / \mathrm{kg}$ daily till reaching $3 \mathrm{~g} / \mathrm{kg} /$ day. Intravenous fat emulsion (intralipid 20\%) is used at a starting rate of $1 \mathrm{~g} / \mathrm{kg}$ only for babies with a birth weight $\leq 750 \mathrm{~g}$ and advanced to a maximum of $2 \mathrm{~g} / \mathrm{kg} /$ day.

\section{Venous Access}

Umbilical venous catheter (UVC) is attempted for all extremely low birth weight infants (ELBW: less than $1000 \mathrm{~g}$ ) and for the majority of VLBW infants and, if successfully placed, is kept in situ for 3 to 7 days. On the day of UVC removal, if the baby is receiving less than $25 \%$ of the target enteral nutrition volume, a peripherally inserted central catheter (PICC) is attempted and, if successfully placed, is kept in situ till reaching and tolerating maximum fortified enteral feeds.

\section{Monitoring}

Infants are weighed on a daily basis at the same time of the day using the same electronic digital scale. Additionally, length and head circumference are measured once a week unless more frequent checks are clinically indicated. Growth parameters are plotted on Fenton premature infant-special growth charts based on the estimated gestational age.

Kidney function tests, electrolytes (sodium, potassium, and calcium), and blood glucose are routinely assessed on a daily basis during the first 3-5 days and then twice a week while receiving TPN. Liver function tests are checked once every two weeks. More frequent monitoring might be done based on the infant's clinical status.

Statistical analyses were performed using IBM SPSS Statistics Software version 25 (IBM Corp., Armonk, NY, USA). Continuous variables were reported as means and standard deviation, whereas categorical variables were reported as frequency distributions and proportions. A $p$ value of 0.05 was considered statistically significant. To examine the significance of association between categorical variables and EUGR, Pearson's chi-square test was used, while Student's $t$-test and ANOVA were applied to examine the significance level for continuous variables.

All variables were compared between EUGR and nonEUGR infants. After identifying the clinical and nutritional factors significantly associated with EUGR (based on $p$ value of $<0.05$ ), a multilogistic regression model was performed and factors with persistent statistical significance 
were determined. Adjusted odds ratios with $95 \%$ confidence intervals (AOR, 95\% C.I.) were accordingly reported.

\section{Results}

A total of 360 VLBW infants were delivered at KAUH during the 5-year study period; 113 were excluded ( 3 transfers, 89 early neonatal deaths, and 21 deaths before reaching 36-week PCA). Of the 247 infants who were included in analysis, 112 (45\%) were males and 210 (85\%) were delivered by CS. The mean birth weight and GA were 1227 $( \pm 205) \mathrm{g}$ and $30.5( \pm 2.6)$ weeks, respectively. ELBW constituted $12 \%$ (30 cases), while 72 (29\%) were SGA at birth. EUGR was diagnosed in 198 cases $(80 \%)$ based on weight, compared to 117 (53\%) based on head circumference and $166(67 \%)$ based on length. Of the SGA infants, EUGR was diagnosed in $97 \%$ (70 out of 72) compared with 73\% (128 out of 175) in the non-SGA group (Table 1).

Table 2 highlights the morbidities among the included infants. Compared with the non-EUGR group, the EUGR infants required invasive mechanical ventilatory support for longer duration (5.7 vs 2.2 days, $p=0.03$ ), were more likely to have sepsis $(23 \%$ vs $10 \%, p<0.05)$, and were discharged from the hospital later ( $46 \pm 25$ vs $38 \pm 15$ days, $p=0.03$ ).

Table 3 demonstrates the feeding patterns and nutritional interventions conducted during the hospital stay. EUGR infants started enteral feeding later (3.7 vs 2.8 days $p=0.05$ ), achieved full enteral feeding at older age (18.1 vs 14.4 days $p=0.02$ ), took more time to regain birth weight (19.6 vs 16.6 days $p=0.03)$, and received less protein intake on the 8 th day of age $(3.2 \mathrm{vs} 3.6 \mathrm{~g} / \mathrm{kg} /$ day $\mathrm{p}=0.009$ ) and less total caloric intake on the 15 th day of life (89 vs $106 \mathrm{kcal} / \mathrm{kg} /$ day $\mathrm{p}=0.005$ ). The weight at discharge was significantly higher in the non-EUGR group ( $1890 \pm 107$ vs $1715 \pm 156 \mathrm{~g}, p=0.005$ ).

After identifying the clinical and nutritional factors significantly associated with EUGR $(p$ value $<0.05$ ), a multilogistic regression model was performed and the factors with persistent statistical significance were determined to include SGA (AOR 9, 95\% C.I. 2, 50), delayed feeding initiation beyond three days (AOR 3.8, 95\% C.I. $1.2,10)$, delayed achievement of full enteral feeding beyond 14 days (AOR 3.3, 95\% C.I. 1.2, 8), protein intake of less than $3 \mathrm{~g} / \mathrm{kg}$ /day on day 8 (AOR 2.1, 95\% C.I. 1.1,

Table I Characteristics of VLBW Infants

\begin{tabular}{|c|c|c|c|c|c|}
\hline Variable & & $\begin{array}{l}\text { Total }(N=247) N(\%) \text { or } \\
\text { Mean }( \pm S D)\end{array}$ & $\begin{array}{l}\text { EUGR }(N=198) N(\%) \text { or } \\
\text { Mean }( \pm S D)\end{array}$ & $\begin{array}{l}\text { Non-EUGR }(N=49) N(\%) \text { or } \\
\text { Mean }( \pm S D)\end{array}$ & $P$ value \\
\hline Gender & $\begin{array}{l}\text { Male } \\
\text { Female }\end{array}$ & $\begin{array}{l}112(45) \\
135(55)\end{array}$ & $\begin{array}{l}89(45) \\
109(55)\end{array}$ & $\begin{array}{l}23(47) \\
26(53)\end{array}$ & 0.8 \\
\hline $\begin{array}{l}\text { Gestational age } \\
\text { (weeks) }\end{array}$ & $\begin{array}{l}\text { Mean (SD) } \\
\leq 32 \\
>32\end{array}$ & $\begin{array}{l}30.5( \pm 2.6) \\
I 76(7 \mid) \\
7 \mid(29)\end{array}$ & $\begin{array}{l}30.7( \pm 2.7) \\
132(67) \\
66(33)\end{array}$ & $\begin{array}{l}29.8( \pm 1.6) \\
44(90) \\
5(10)\end{array}$ & $\begin{array}{l}0.04 \\
0.001\end{array}$ \\
\hline $\begin{array}{l}\text { Birth weight } \\
\text { (g) }\end{array}$ & $\begin{array}{l}\text { Mean (SD) } \\
\text { ELBW } \\
\text { VLBW }\end{array}$ & $\begin{array}{l}1227( \pm 205) \\
30(12) \\
217(88)\end{array}$ & $\begin{array}{l}1209( \pm 213) \\
29(15) \\
169(85)\end{array}$ & $\begin{array}{l}1300( \pm \mid 48) \\
\text { I }(2) \\
48(98)\end{array}$ & $\begin{array}{l}0.005 \\
0.016\end{array}$ \\
\hline SGA & $\begin{array}{l}\text { Yes } \\
\text { No }\end{array}$ & $\begin{array}{l}72(29) \\
I 75(7 I)\end{array}$ & $\begin{array}{l}70(35) \\
128(65)\end{array}$ & $\begin{array}{l}2(4) \\
47(96)\end{array}$ & 0.005 \\
\hline $\begin{array}{l}\text { Assisted } \\
\text { pregnancy }\end{array}$ & $\begin{array}{l}\text { Yes } \\
\text { No }\end{array}$ & $\begin{array}{l}60(24) \\
187(76)\end{array}$ & $\begin{array}{l}47(24) \\
I 5 \mid(76)\end{array}$ & $\begin{array}{l}13(27) \\
36(73)\end{array}$ & 0.68 \\
\hline $\begin{array}{l}\text { Mode of } \\
\text { delivery }\end{array}$ & $\begin{array}{l}\text { VD } \\
C S\end{array}$ & $\begin{array}{l}37(15) \\
210(85)\end{array}$ & $\begin{array}{l}34(17) \\
164(83)\end{array}$ & $\begin{array}{l}3(6) \\
46(94)\end{array}$ & 0.05 \\
\hline $\begin{array}{l}\text { Number of } \\
\text { gestation }\end{array}$ & $\begin{array}{l}\text { Singleton } \\
\text { Multiples }\end{array}$ & $\begin{array}{l}\text { II } 3(46) \\
134(54)\end{array}$ & $\begin{array}{l}88(44) \\
110(56)\end{array}$ & $\begin{array}{l}25(5 I) \\
24(49)\end{array}$ & 0.4 \\
\hline $\begin{array}{l}\text { Antenatal } \\
\text { steroids }\end{array}$ & $\begin{array}{l}\text { Yes } \\
\text { No }\end{array}$ & $\begin{array}{l}55(22) \\
192(78)\end{array}$ & $\begin{array}{l}44(22) \\
154(78)\end{array}$ & $\begin{array}{l}11(22) \\
38(78)\end{array}$ & 0.97 \\
\hline
\end{tabular}

Abbreviations: VLBW, very low birth weight; ELBW, extremely low birth weight; SGA, small for gestational age; EUGR, extrauterine growth restriction; VD, vaginal delivery; CS, cesarean section. 
Table 2 Complications and Morbidities

\begin{tabular}{|c|c|c|c|c|}
\hline Variable & $\begin{array}{l}\text { Total }(N=247) N(\%) \text { or } \\
\text { Mean }( \pm S D)\end{array}$ & $\begin{array}{l}\text { EUGR }(N=\mid 98) N(\%) \text { or } \\
\text { Mean }( \pm S D)\end{array}$ & $\begin{array}{l}\text { Non-EUGR }(N=49) N(\%) \text { or } \\
\text { Mean }( \pm S D)\end{array}$ & $P$ value \\
\hline Severe IVH & $38(15)$ & $33(17)$ & $5(10)$ & 0.08 \\
\hline Patent ductus arteriosus & $93(37)$ & $78(39)$ & $15(31)$ & 0.25 \\
\hline Mechanical ventilation & $5( \pm 10)$ & $5.69(I I .4)$ & $2.2(2.7)$ & 0.03 \\
\hline$\leq 3$ days & $67(27)$ & $46(23)$ & $21(43)$ & 0.02 \\
\hline$>3$ days & $83(33)$ & $70(35)$ & $13(26)$ & \\
\hline CPAP days & $15( \pm 16)$ & I5.6 (I7.3) & $12.5(\mathrm{II})$ & 0.12 \\
\hline UVC days & $1.94( \pm 2.8)$ & $2(2.9)$ & I.7 (2.5) & 0.5 \\
\hline Systemic steroids & $35(14)$ & $30(15)$ & $5(10)$ & 0.37 \\
\hline Necrotizing enterocolitis & $5(2)$ & $4(2)$ & I (2) & 0.99 \\
\hline Sepsis & $50(20)$ & $45(23)$ & $5(10)$ & 0.05 \\
\hline Blood transfusion & $168(68)$ & $137(69)$ & $31(63)$ & 0.42 \\
\hline Length of stay (days) & $44.9( \pm 24)$ & $46(25)$ & $38(15)$ & 0.03 \\
\hline
\end{tabular}

Abbreviations: EUGR, extrauterine growth restriction; IVH, intraventricular hemorrhage; CPAP, continuous positive airway pressure; UVC, umbilical venous catheter.

Table 3 Nutritional Interventions During NICU Stay

\begin{tabular}{|c|c|c|c|}
\hline Variable & EUGR $(N=198) N(\%)$ or Mean ( $N S D)$ & Non-EUGR $(N=49) N(\%)$ or Mean $( \pm S D)$ & $P$ value \\
\hline Age of enteral feeding Initiation & $3.7( \pm 3.1)$ & $2.8( \pm 2.7)$ & 0.09 \\
\hline$\leq 3$ days & $120(6 \mid)$ & $40(82)$ & 0.05 \\
\hline$>3$ days & $78(39)$ & $9(18)$ & \\
\hline Time to full enteral feeds & $18.1( \pm 10.5)$ & $14.4( \pm 6.2)$ & 0.02 \\
\hline$\leq 14$ days & $82(4 I)$ & $28(57)$ & 0.04 \\
\hline$>14$ days & $116(59)$ & $21(43)$ & \\
\hline Days to regain birth weight & $19.6( \pm I I)$ & $16.6( \pm 7)$ & 0.03 \\
\hline Protein intake on day I (g/kg) & $0.97( \pm 0.9)$ & I.I $( \pm 0.8)$ & 0.3 \\
\hline Caloric intake on day I (kcal/kg) & $35( \pm 5.3)$ & $35( \pm 5)$ & 0.98 \\
\hline Protein intake on day $8(\mathrm{~g} / \mathrm{kg})$ & $3.2( \pm 1.1)$ & $3.6( \pm 0.9)$ & 0.009 \\
\hline Caloric intake on day $8(\mathrm{kcal} / \mathrm{kg})$ & $71( \pm 13)$ & $73( \pm 15)$ & 0.48 \\
\hline Protein intake on day $15(\mathrm{~g} / \mathrm{kg})$ & $3.9( \pm 1.2)$ & $4.2( \pm I)$ & 0.12 \\
\hline Caloric intake on day I5 (kcal/kg) & $89( \pm 15)$ & $106( \pm 13)$ & 0.005 \\
\hline Protein intake at discharge $(\mathrm{g} / \mathrm{kg})$ & $4( \pm I)$ & $4.3( \pm I)$ & 0.09 \\
\hline Weight at discharge (g) & $1715( \pm 107)$ & $1890( \pm 156)$ & 0.005 \\
\hline
\end{tabular}

Abbreviations: NICU, neonatal intensive care unit; EUGR, extrauterine growth restriction.

4.1), total caloric intake of less than $100 \mathrm{kcal} / \mathrm{kg} / \mathrm{day}$ on day 15 (AOR 3.8, 95\% C.I. 1.6, 8.9), and history of sepsis (AOR 3, 95\% C.I. 1.1, 9) (Table 4). Of these factors, delayed feeding initiation beyond three days, $<100 \mathrm{kcal} / \mathrm{kg}$ of caloric intake on day 15 , and the occurrence of sepsis continue to be positively associated with EUGR after performing a separate analysis among the non-SGA infants (Table 5).

\section{Discussion}

This retrospective analysis represents the first review from Jordan and the region that highlights the main clinical and nutritional determinants of EUGR, a serious problem that affected $80 \%$ of our VLBW infant population. Suboptimal nutritional support during the first two weeks was identified as the main predisposing factor.

In this report, $80 \%$ of VLBW infants were diagnosed with EUGR based on weight. The rate is reduced to $67 \%$ based on length and $56 \%$ according to head circumference. The reported rates of EUGR in different studies vary depending on the used definition and the inclusion criteria. ${ }^{7}$ A weight below the 10 th percentile at 28 days of life, at a PCA of 36 weeks or 40 weeks, or at discharge have been utilized by different reports in calculating the 
Table 4 Multilogistic Regression Model of the Clinical and Nutritional Factors Associated with EUGR $(n=247)$

\begin{tabular}{|c|c|c|c|c|}
\hline & Variable & $P$ value & AOR & 95\% C.I. \\
\hline SGA & $\begin{array}{l}\text { No } \\
\text { Yes }\end{array}$ & 0.012 & $\begin{array}{l}\text { ref } \\
9\end{array}$ & $(2,50)$ \\
\hline $\begin{array}{l}\text { Age at feeding initiation } \\
\text { (days) }\end{array}$ & $\begin{array}{l}\leq 3 \\
>3\end{array}$ & 0.007 & $\begin{array}{l}\text { ref } \\
3.8\end{array}$ & $(1.2,10)$ \\
\hline $\begin{array}{l}\text { Age at full feeds } \\
\text { (days) }\end{array}$ & $\begin{array}{l}\leq 14 \\
>14\end{array}$ & 0.008 & $\begin{array}{l}\text { ref } \\
3.3\end{array}$ & $(1.2,8)$ \\
\hline $\begin{array}{l}\text { Protein intake on day } 8 \\
(\mathrm{~g} / \mathrm{kg})\end{array}$ & $\begin{array}{l}>3 \\
\leq 3\end{array}$ & 0.02 & $\begin{array}{l}\text { ref } \\
2.1\end{array}$ & $(I . I, 4 . I)$ \\
\hline $\begin{array}{l}\text { Caloric intake on day I5 } \\
(\mathrm{kcal} / \mathrm{kg})\end{array}$ & $\begin{array}{l}>100 \\
\leq 100\end{array}$ & 0.002 & $\begin{array}{l}\text { ref } \\
3.8\end{array}$ & $(1.6,8.9)$ \\
\hline Sepsis & $\begin{array}{l}\text { No } \\
\text { Yes }\end{array}$ & 0.03 & $\begin{array}{l}\text { ref } \\
3\end{array}$ & $(I . I, 9)$ \\
\hline
\end{tabular}

Abbreviations: EUGR, extrauterine growth restriction; AOR, adjusted odds ratio; SGA, small for gestational age.

Table 5 Multilogistic Regression Model of the Clinical and Nutritional Factors Associated with EUGR Among the NonSGA Infants $(n=175)$

\begin{tabular}{|l|l|l|l|l|}
\hline & Variable & P value & AOR & 95\% C.I. \\
\hline $\begin{array}{l}\text { Age at feeding initiation } \\
\text { (days) }\end{array}$ & $\leq 3$ & & Ref & \\
\hline 3 & 0.01 & 3.4 & $(\mathrm{I.3}, 8)$ \\
\hline $\begin{array}{l}\text { Caloric intake on day 15 } \\
\text { (kcal/kg) }\end{array}$ & $\begin{array}{l}>100 \\
\leq 100\end{array}$ & 0.006 & $\begin{array}{l}\text { Ref } \\
4\end{array}$ & $(\mathrm{I} .5,10)$ \\
\hline Sepsis & No & & $\begin{array}{l}\text { Ref } \\
3\end{array}$ & $(\mathrm{I.2,9.1)}$ \\
\hline
\end{tabular}

Abbreviations: EUGR, extrauterine growth restriction; AOR, adjusted odds ratio; SGA, small for gestational age.

incidence of EUGR. ${ }^{7}$ Stoll et al reported a rate of $79 \%$ among extremely preterm infants (less than 28 weeks) included in the NICHD network. ${ }^{19}$ In a recent report from Italy, EUGR was diagnosed in $71 \%$ and $50 \%$ of less than 34-week infants based on weight and head circumference at discharge, respectively. ${ }^{12}$ One of the main factors for development of EUGR is the inadequate nutritional status at birth. The rate of EUGR among SGA infants included in our study was $97 \%$ (70 out of 72) compared with $73 \%$ (128 out of 175) in non-SGA. This finding was reflected by a greater mean GA in the EUGR group (30.7 vs 29.8 weeks). The correlation between SGA at birth and EUGR at discharge has been emphasized in other reports. ${ }^{20}$ Figueras-Aloy et al used the term "true EUGR" to differentiate EUGR related to postnatal growth failure among AGA infants from pre-programmed EUGR related to inadequate antenatal nutritional status among SGA infants. ${ }^{2}$

Although prematurity-related co-morbidities contribute to the occurrence of EUGR, inadequate nutritional support remains the major predisposing factor. ${ }^{2,5}$ In our study, we confirmed that suboptimal protein and total caloric intake in the first two weeks of life were strongly linked to EUGR at discharge. Our protocol is to provide all VLBW infants with $1 \mathrm{~g} / \mathrm{kg}$ of intravenous protein starting on the first day of life and gradually increasing the supplement to $3 \mathrm{~g} / \mathrm{kg} /$ day over a period of three days. Protein remains the most essential macronutrient needed for the growth of all body organs including the brain. ${ }^{21}$ Studies have confirmed that parenteral nutrition containing $3 \mathrm{~g} / \mathrm{kg} /$ day initiated on the first day of life would reduce the postnatal growth restriction and subsequently improve growth and developmental outcomes in infancy and early childhood. ${ }^{22,23}$ Despite compliance with reaching the maximum recommended daily allowance of 3-4 g/ $\mathrm{kg} / \mathrm{day}$ of intravenous protein in premature infants to maintain positive nitrogen balance, the non-aggressive protocol in our unit could have contributed to the higher rate of EUGR observed in our infant population. The absence of proper TPN service to provide infants with premixed TPN solutions in addition to the restricted use of intravenous lipid supply to the $<750$-g extremely premature infants in our unit plays an important role. Early provision of intravenous lipid and daily advancement of supplement to $3 \mathrm{~g} / \mathrm{kg} /$ day are proven to be strongly associated with better growth and development at one year of life. ${ }^{20}$

The present study emphasized the importance of early initiation of enteral feeding and fast achievement of full enteral feeds in faster regaining of birth weight and ultimately reducing the rate of EUGR. Enteral feeding in preterm infants has been linked to development of NEC, and this unsubstantiated concern drives some neonatologists to be extra cautious in advancing feeding, a trend that negatively impacts the caloric intake and the growth rate. However, several studies have proposed that the more aggressive approach of enteral feeding results in better growth outcomes without increasing the incidence of NEC. ${ }^{24-26}$ In our study, the rate of EUGR was $90 \%$ among infants with $>3$-day delay in enteral feeding initiation compared with $75 \%$ among those who started feeding within the first three days after birth. Despite our approach of early initiation of feeds, the frequent interruptions of enteral feeds has a major negative impact by extending the 
time required to reach full feeds and to regain birth weight. Our findings are consistent with several other studies. For example, Wang et al studied the growth patterns among Chinese VLBW infants and concluded that a positive nutritional support manifested by early enteral feeding has resulted in faster regain of birth weight with less risk of EUGR and shorter hospital stay. ${ }^{27}$

This study emphasized the need to follow the current nutritional recommendations that involve prompt provision of parenteral nutrition including carbohydrate, lipid, and high-dose protein to deliver the optimal protein and protein/energy ratio in the immediate postnatal period. ${ }^{28}$ Early establishment of enteral feeds should be the next target to maintain positive protein and total energy balance in order to achieve and maintain an optimal growth rate in premature infants. ${ }^{3,21,29}$ By applying a strategic modification of nutritional protocols among VLBW infants, other neonatal morbidities and the duration of hospitalization are also expected to improve. ${ }^{27,30}$

The main limitation of this study is that it is a singlecenter retrospective analysis. Data collection about nutritional intake relied mainly on electronic documentation and might not be accurate all the time. Although the number of included infants is reasonable, the generalizability of our findings remains an issue with the variation in clinical practice in the absence of national guidelines about the proper nutritional support for premature infants. Also, the absence of proper TPN service at our unit has a major influence on the nutritional support of our included infants and probably has significantly contributed to the high EUGR in our analysis. In addition, this study used the cross-sectional definition of EUGR based on weight values at the time of discharge, and this might have overestimated the true EUGR rate. The longitudinal definition, based on growth velocity and $z$ score difference, more accurately reflects the actual postnatal growth pattern and gives more valid results and conclusions. Another limitation is the short-term analysis of the growth pattern among EUGR patients during the hospital stay. Since the majorities were SGA, a catch-up in growth velocity is expected, and so longer follow-up after discharge is needed.

\section{Conclusions and Recommendations}

The rate of EUGR in our VLBW infants is high. In-utero growth restriction is the most significant determinant of postnatal growth failure. In addition, AGA-VLBW infants are at significant risk of EUGR if they receive suboptimal nutritional supply during the first 14 days of life. More structured guidelines with modifications of nutritional protocol to focus on more consistent early initiation of enteral feeds with minimal interruption, maximizing intravenous protein supply to $3 \mathrm{~g} / \mathrm{kg} /$ day on the first day after birth, and increasing energy intake by providing intravenous lipid to all VLBW infants and utilizing milk fortifiers are expected to improve the postnatal growth pattern, reduce the incidence of EUGR, and ultimately improve growth and neurodevelopment in infancy and early childhood. ${ }^{10}$ In addition, efforts should be targeted to establish a local or national TPN service unit capable of preparing premixed TPN solutions on a daily basis. This will provide infants with their actual requirements of macronutrients and micronutrients to ensure delivering the recommended energy according to their weight, age, and overall clinical status. With adequate nutrition and better weight gain, premature infants can be discharged home earlier, a more cost-effective strategy that should be highlighted at a national level. A multi-center prospective study is highly recommended to better study the nutritional outcomes among the Jordanian neonatal population.

\section{Data Sharing Statement}

The datasets used and/or analyzed during the current study are available from the corresponding author on reasonable request.

\section{Ethics Approval and Informed Consent}

An Institutional Review Board (IRB) approval was obtained from Jordan University of Science and Technology (IRB number 518-2020). Also, administrative approval was obtained from KAUH to review the electronic medical records. Parental consent was waived as this study involves chart review and analysis was performed on de-identified data. Patient data privacy and confidentiality are maintained as this study was conducted in compliance with the ethical standards per Helsinki declaration.

\section{Author Contributions}

All authors contributed to data analysis, drafting or revising the article, have agreed on the journal to which the article will be submitted, gave final approval of the version to be published, and agree to be accountable for all aspects of the work. 


\section{Disclosure}

All authors declare that they have no competing interest.

\section{References}

1. Rasmussen KM, Yaktine AL, Guidelines I of M (US) and NRC (US) $\mathrm{C}$ to RIPW. Composition and components of gestational weight gain: physiology and metabolism; 2009. Available from: https://www.ncbi. nlm.nih.gov/books/NBK32815/. Accessed September 22, 2020.

2. Figueras-Aloy J, Palet-Trujols C, Matas-Barceló I, Botet-Mussons F, Carbonell-Estrany X. Extrauterine growth restriction in very preterm infant: etiology, diagnosis, and 2-year follow-up. Eur J Pediatr. 2020;179(9):1469-1479. doi:10.1007/s00431-020-03628-1.

3. Kleinman RE, Greer FR. Pediatric nutrition: policy of the American Academy of Pediatrics (Book, 2014). Available from: https://www.ncbi. nlm.nih.gov/nlmcatalog/101653189. Accessed September 23, 2020.

4. Su BH. Optimizing nutrition in preterm infants. Pediatr Neonatol. 2014;55(1):5-13. doi:10.1016/j.pedneo.2013.07.003

5. Hu F, Tang Q, Wang Y, et al. Analysis of nutrition support in very low-birth-weight infants with extrauterine growth restriction. Nutr Clin Pract. 2019;34(3):436-443. doi:10.1002/ncp.10210.

6. Jobe AH. Let's feed the preterm lung. $J$ Pediatr (Rio J). 2006;82:165-166. doi:10.2223/JPED.1481.

7. Peila C, Spada E, Giuliani F, et al. Extrauterine growth restriction: definitions and predictability of outcomes in a cohort of very low birth weight infants or preterm neonates. Nutrients 2020:12. doi:10.3390/nu12051224.

8. Griffin IJ, Tancredi DJ, Bertino E, Lee HC, Profit J. Postnatal growth failure in very low birthweight infants born between 2005 and 2012. Arch Dis Child Fetal Neonatal Ed. 2016;101(1):F50-5. doi:10.1136/ archdischild-2014-308095.

9. Horbar JD, Ehrenkranz RA, Badger GJ, et al. Weight growth velocity and postnatal growth failure in infants 501 to 1500 grams: 2000-2013. Pediatrics 2015;136(1):e84-92. doi:10.1542/peds.2015-0129.

10. Chien HC, Chen CH, Wang TM, Hsu YC, Lin MC. Neurodevelopmental outcomes of infants with very low birth weights are associated with the severity of their extra-uterine growth retardation. Pediatr Neonatol. 2018;59(2):168-175. doi:10.1016/j. pedneo.2017.08.003

11. Leppänen M, Lapinleimu H, Lind A, et al. Antenatal and postnatal growth and 5-year cognitive outcome in very preterm infants. Pediatrics 2014;133(1):63-70. doi:10.1542/peds.2013-1187

12. Tozzi MG, Moscuzza F, Michelucci A, et al. ExtraUterine Growth Restriction (EUGR) in preterm infants: growth patterns, nutrition, and epigenetic markers. A Pilot Study. Front Pediatr. 2018;6:408. doi:10.3389/fped.2018.00408.

13. Clark RH, Thomas P, Peabody J. Extrauterine growth restriction remains a serious problem in prematurely born neonates. Pediatrics. 2003;111(5):I:986-90. doi:10.1542/peds.111.5.986

14. Kumar RK, Singhal A, Vaidya U, Banerjee S, Anwar F, Rao S. Optimizing nutrition in preterm low birth weight infants-consensus summary. Front Nutr. 2017;4:20. doi:10.3389/fnut.2017.00020.
15. Miller M, Donda K, Bhutada A, Rastogi D, Rastogi S. Transitioning preterm infants from parenteral nutrition: a comparison of 2 protocols. J Parenter Enteral Nutr. 2017;41(8):1371-1379. doi:10.11 $77 / 0148607116664560$

16. Coverston CR, Schwartz R. Extrauterine growth restriction: a continuing problem in the NICU. MCN Am J Matern Child Nurs. 2005;30(2):101-106. doi:10.1097/00005721-200503000-00006.

17. Al-lawama M, Abu Alrous H, Alkhatib H, et al. Nutritional support of very low birth weight infants in a tertiary center in a developing country. J Clin Med Res. 2019;11:283-288.

18. Fenton TR, Kim JH. A systematic review and meta-analysis to revise the fenton growth chart for preterm infants. BMC Pediatr. 2013;13 (1):59. doi:10.1186/1471-2431-13-59.

19. Stoll BJ, Hansen NI, Bell EF, et al. Neonatal outcomes of extremely preterm infants from the NICHD neonatal research network. Pediatrics 2010;126(3):443-456. doi:10.1542/peds.2009-2959.

20. Ehrenkranz RA. Extrauterine growth restriction: is it preventable? J Pediatr (Rio J). 2014;90(1):1-3. doi:10.1016/j.jped.2013.10.003.

21. Hay WW. Nutritional support strategies for the preterm infant in the neonatal intensive care unit. Pediatr Gastroenterol Hepatol Nutr. 2018;21(4):234-247. doi:10.5223/pghn.2018.21.4.234.

22. Thureen PJ, Melara D, Fennessey PV, Hay WW. Effect of low versus high intravenous amino acid intake on very low birth weight infants in the early neonatal period. Pediatr Res. 2003;53(1):24-32. doi:10. 1203/00006450-200301000-00008.

23. Denne SC, Poindexter BB. Evidence supporting early nutritional support with parenteral amino acid infusion. Semin Perinatol. 2007;31(2):56-60. doi:10.1053/j.semperi.2007.02.005.

24. Chauhan M, Henderson G, McGuire W. Enteral feeding for very low birth weight infants: reducing the risk of necrotising enterocolitis. Arch Dis Child Fetal Neonatal Ed. 2008;93. doi:10.1136/adc.2007. 115824.

25. Abbott J, Berrington JE, Boyle E, McGuire W. Early enteral feeding strategies for very preterm infants: current evidence from cochrane reviews. Arch Dis Child Fetal Neonatal Ed. 2013;98 1. F470-472

26. Lin HY, Chang JH, Chung MY, Lin HC. Prevention of necrotizing enterocolitis in preterm very low birth weight infants: is it feasible? J Formos Med Assoc. 2014;113(8):490-497. doi:10.1016/j.jfma.20 13.03.010

27. Wang XM, Zhu YP, Wang L. Effect of positive nutritional support strategy on extrauterine growth restriction in preterm infants. Zhongguo Dang Dai Er Ke Za Zhi. 2013;15:1054-1058. doi:10.7499/j.issn.1008-8830.2013.12.004.

28. Patel P, Bhatia J. Total parenteral nutrition for the very low birth weight infant. Semin Fetal Neonatal Med. 2017;22(1):2-7. doi:10.10 16/j.siny.2016.08.002.

29. Piwoszkin LM, Lash ML, Kim M, Kampanatkosol R. Revised standardized nutrition in very low birth weight infants. Pediatrics. 2018;141(1):558. doi:10.1542/peds.141.1_MeetingAbstract.558.

30. Choi AY, Lee YW, Chang MY. Modification of nutrition strategy for improvement of postnatal growth in very low birth weight infants. Korean J Pediatr. 2016;59(4):165-173. doi:10.3345/kjp.2016.59. 4.165 .
International Journal of General Medicine

\section{Publish your work in this journal}

The International Journal of General Medicine is an international, peer-reviewed open-access journal that focuses on general and internal medicine, pathogenesis, epidemiology, diagnosis, monitoring and treatment protocols. The journal is characterized by the rapid reporting of reviews, original research and clinical studies across all disease areas. The manuscript management system is completely online and includes a very quick and fair peer-review system, which is all easy to use. Visit http://www.dovepress.com/ testimonials.php to read real quotes from published authors. 